\title{
Impact of a high-fat diet on intestinal stem cells and epithelial barrier function in middle-aged female mice
}

\author{
YU XIE* , FEI DING* , WENJUAN DI, YIFAN LV, FAN XIA, YUNLU SHENG, JING YU and GUOXIAN DING \\ Department of Geriatrics, Division of Geriatric Endocrinology, The First Affiliated Hospital of \\ Nanjing Medical University, Nanjing, Jiangsu 210029, P.R. China
}

Received May 24, 2019; Accepted December 6, 2019

DOI: $10.3892 / \mathrm{mmr} .2020 .10932$

\begin{abstract}
A high-fat diet (HFD) or obesity-promoting diet is closely associated with metabolic diseases and intestinal tumors, particularly in middle-aged individuals (typically 45-64 years old). The intestinal epithelium constitutes a barrier that separates the host from the food and microbiota in the gut, and thus, a dysfunctional epithelium is associated with a number of diseases. However, the changes caused to the function of intestinal epithelium in response to an HFD have not been well-studied to date. In the present study, middle-aged female mice (12 months old) fed an HFD for a period of 14 weeks were used to determine the effects of HFD on the intestine. Characteristics including the body weight, fat deposition, glucose metabolism, inflammatory state and intestinal morphology were assessed, while the intestinal stem cell (ISC) counts and the ability of isolated intestinal crypts to form organoid bodies in 3D culture were examined. Intestinal epithelial barrier function, including secretory defense, tight junctions and cell apoptosis, were also studied. Morphologically, the HFD resulted in a mild reduction in the length of villi of the small intestine, the colon length and the depth of colon crypts. In addition, the ISC counts were increased in the small intestine and colon in HFD-fed mice. The ability of crypts to grow into organoids (mini-guts) was also increased in crypts obtained from mice fed an HFD, while HFD compromised the epithelial barrier function of the colon. These results demonstrated how an HFD affects the intestinal epithelium and highlighted the need to carefully consider dietary patterns.
\end{abstract}

Correspondence to: Professor Guoxian Ding or Dr Jing Yu, Department of Geriatrics, Division of Geriatric Endocrinology, The First Affiliated Hospital of Nanjing Medical University, 300 Guangzhou Road, Nanjing, Jiangsu 210029, P.R. China

E-mail: dinggx@njmu.edu.cn

E-mail: yujing@njmu.edu.cn

${ }^{*}$ Contributed equally

Key words: high-fat diet, intestinal stem cells, organoids, barrier function, middle-aged female mice

\section{Introduction}

The association of the consumption of a high-fat diet (HFD) or obesity promoting diet with metabolic disorders, such as obesity, diabetes, hypertension and cardiovascular diseases, has long been recognized (1). A large number of studies have suggested that an HFD also affects the severity of tumorigenesis in the gut, particularly in colon cancer, independent of obesity (2). However, little is known regarding changes in the intestinal epithelium in response to HFD ingestion, both in the small intestine and colon.

The intestinal tract is the first point of contact of ingested food, and thus disturbances in gut homeostasis may represent the first point in a chain of events resulting in diseases associated with HFD (3). An increasing number of studies have demonstrated that changes in diet are manifested quickly as changes to the composition of the gut microbiota $(4,5)$, whose composition is associated with a variety of diseases $(6,7)$. Diet, gut microbiota and host interactions that occur at intestinal epithelial cells (IECs) serve pivotal roles in shaping the microbial ecology (8). Indeed, IECs constitute a barrier surface that separates the host from the external environment and conserves the host-microbial interactions and tissue homeostasis (9). Therefore, IECs are crucial mediators that maintain the host-commensal microbial relationship and immune cell homeostasis in the intestine. Therefore, the aim of the present study was to determine the effects of an HFD on the function of IECs.

Weight gain accompanied by an increased tendency for central fat distribution is more common among women than in men, particularly in middle-aged individuals, with an age of approximately 45-64 years. Bjerregaard et al (10) reported that being overweight at the age of 7 years was associated with an increased risk of developing type 2 diabetes as an adult only if the individual continued to be overweight until puberty or at a later age. Therefore, weight gain in middle-aged individuals is more harmful and more closely associated with cardiovascular diseases and type 2 diabetes (10). Previously, HFD models were induced in mice with an age of approximately 2-3 months, and thus the effects of aging on disease progression have rarely been taken into consideration.

Therefore, in the present study, middle-aged female mice (12-month-old) were fed an HFD for a period of 14 weeks to investigate how HFD influenced the gut pathophysiology, 
as well as obesity-associated metabolic dysfunction and disorders. The results revealed that HFD increased the intestinal stem cell (ISC) counts and crypt function in the small intestine and colon, and compromised the epithelial barrier function of the colon. These findings may be helpful in understanding how an HFD influences the intestinal epithelium in maintaining tissue homeostasis and suggested the importance of careful consideration of dietary habits.

\section{Materials and methods}

Animal studies. A total of 14 female C57BL/6J mice were purchased from the Model Animal Research Center of Nanjing University (Nanjing, China). At 12 months of age and at an average weight of $32.0 \mathrm{~g}$, the mice were randomly assigned to the regular diet $(n=6)$ or HFD $(n=8)$ group and provided their respective diet for 14 weeks. The HFD consisted of $60 \%$ calories as fat, $20 \%$ as carbohydrate and $20 \%$ as protein. Water was freely available at all times. Mice were housed at $23 \pm 1^{\circ} \mathrm{C}$ with an average humidity of $60 \pm 1 \%$ and a $12-\mathrm{h}$ light/dark cycle. The body weight and food intake of animals were measured weekly. At the end of the feeding period, mice were anesthetized with intraperitoneal injection of sodium pentobarbital at a dose of $50-90 \mathrm{mg} / \mathrm{kg}$ of body weight and then sacrificed by cervical dislocation, followed by additional removal of the heart to ensure death. The experimental protocols of the present study were approved by the Animal Care and Use Committee of Nanjing Medical University (Nanjing, China), and conducted in accordance with the guidelines of this committee.

Oral glucose tolerance test (oGTT) and insulin tolerance test (ITT). For oGTT, mice were fasted overnight (14-18 h) and then given a glucose load (25\% stock solution in saline) of $2 \mathrm{~g}$ per $\mathrm{kg}$ of body weight by oral administration. For ITT, intraperitoneal injection of an insulin bolus of 4 IU per $\mathrm{kg}$ of body weight was performed. Blood samples were collected from the tail vein at $0,15,30,60$ and 120 min after administration of glucose or insulin. Plasma glucose concentration was measured using an Accu-Chek Aviva system (Roche Diagnostics).

Cell staining, immunohistochemical and immunofluorescence assays. Mice were weighed and euthanized, and then the small intestine and colon were removed. Next, the lengths of the small intestine (from the pylori to the ileocecal junction) and the colon (from the cecum to the rectum) were measured. From the small intestine, the initial $5 \mathrm{~cm}$ from the pylorus associated with the pancreas was discarded in order to avoid autolytic changes. The following $1.5 \mathrm{~cm}$ corresponding to the portion of proximal jejunum, which represents the majority of the small intestine, was collected. For the colon, $1 \mathrm{~cm}$ at the middle of the colon was dissected for histological analysis. The small intestine and colon samples were fixed in Carnoy's solution composed of ethanol and glacial acetic acid (3:1) at room temperature for $30 \mathrm{~min}$ and stored overnight at $4^{\circ} \mathrm{C}$. The fixed intestine was cut transversely into three (small intestine) or two (colon) $0.5 \mathrm{~cm}$ segments and embedded in paraffin. Subsequently, paraffin-embedded tissues were sliced into 6- $\mu \mathrm{m}$ sections for cross-sectional histological analysis. Tissue sections were deparaffinized with xylene and rehydrated in a descending alcohol series of 100, 95, 80, 70 and 50\%. For heat-induced antigen retrieval, the sections were incubated twice in antigen retrieval buffer $(0.1 \mathrm{M}$ sodium citrate, $0.1 \mathrm{M}$ citric acid, $\mathrm{pH} 6.0$ ) for $10 \mathrm{~min}$ at $90-100^{\circ} \mathrm{C}$. These initial processing steps were the same for all the staining procedures described below and all staining procedures were performed on the same samples, but different sections (3-5 sections used for each staining technique).

Hematoxylin and eosin (H\&E) staining was performed for morphological analyses using standard histological protocols (11). Briefly, tissue sections were stained in hematoxylin solution for $8 \mathrm{~min}$ at room temperature and counterstained with eosin solution for 30-60 sec at room temperature. Stained sections were observed under a light microscope at $x 40$ magnification. The villus length was measured from the base to the top of the villi, and the crypt depth was measured between the crypt-villus junction and the base of the crypt.

Goblet cell quantification was performed using the histochemical Periodic Acid-Schiff (PAS) staining kit (Baso Biotech Co., Ltd.) according to the manufacturer's protocol. Briefly, tissue sections were sequentially stained with Alcian blue solution ( $\mathrm{pH}$ 2.5) for $10 \mathrm{~min}$, Periodic acid solution for $10 \mathrm{~min}$, Schiff reagent for $20 \mathrm{~min}$ and Mayer's hematoxylin solution for $5 \mathrm{~min}$, all at room temperature. Stained cells were observed using a light microscope at x20 magnification.

For immunohistochemical analysis, following the initial processing steps, sections were blocked with $7.5 \%$ goat serum (Boster Biological Technology) for $30 \mathrm{~min}$ at room temperature. Subsequently, sections were incubated overnight at $4^{\circ} \mathrm{C}$ with the following primary antibodies: Anti-Ki67 (1:200; cat. no. GB13030-2; Wuhan Servicebio Technology Co., Inc.), anti-p21 Cip 1 (1:200; cat. no. DF6423; Affinity Biosciences) and anti-p53 (1:200; cat. no. AF0879; Affinity Biosciences). Following the primary antibody incubation, the slides were incubated with a horseradish peroxidase-conjugated secondary antibody (1:300; cat. no. ZB-2301; ZSGB-BIO; OriGene Technologies, Inc.) at $37^{\circ} \mathrm{C}$ for $20 \mathrm{~min}$. Sections were subsequently stained with 3',3'-diaminobenzidine (DAB; $0.05 \%$ DAB, $0.015 \% \mathrm{H}_{2} \mathrm{O}_{2}, 0.01 \mathrm{M} \mathrm{PBS}, \mathrm{pH}$ 7.2) at room temperature for 1-3 min and observed under a light microscope at $\mathrm{x} 40$ magnification.

For immunofluorescence staining, the blocking process was the same as described above for immunohistochemical analysis. Tissue sections were incubated overnight at $4^{\circ} \mathrm{C}$ with the following primary antibodies: Anti-zona occludens 1 (ZO-1) tight junction protein (1:200; cat. no. ab216880; Abcam), anti-Claudin-2 (1:200; cat. no. ab53032; Abcam) and anti-Lgr5/GPR49 (1:200; cat. no. ab NBP1-28904; Novus Biologicals, LLC) antibody. Following the primary antibody incubation, the sections were subsequently incubated with $\mathrm{Cy}^{\mathrm{TM}} 3$-conjugated anti-rabbit immunoglobulin $\mathrm{G}$ heavy and light chain secondary antibody (1:200; cat. no. 111-165-003; Jackson Immuno Research Laboratories, Inc.) at room temperature for 1.5-2 $\mathrm{h}$. The nucleus was counterstained using DAPI (1:1,000; cat. no. D1306; Thermo Fisher Scientific, Inc.) for $5 \mathrm{~min}$ at room temperature and the sections were mounted using VECTASHIELD ${ }^{\circledR}$ antifade mounting medium (Vector Laboratories, Inc.; Maravai LifeSciences) and a coverslip. The 
fluorescence was observed under a fluorescent microscope at x40 magnification.

TUNEL. A TUNEL assay (DeadEnd ${ }^{\mathrm{TM}}$ Fluorometric TUNEL System; Promega Corporation) was conducted to measure the rate of apoptosis according to the manufacturer's protocol. In addition to the fixation and deparaffinization steps described above, tissue sections were subsequently fixed with $4 \%$ formaldehyde in PBS for $15 \mathrm{~min}$ at room temperature. Sections were then permeabilized with $20 \mu \mathrm{g} / \mathrm{ml}$ Proteinase K solution for $10 \mathrm{~min}$ at room temperature and fixed for a second time with $4 \%$ formaldehyde in PBS for $5 \mathrm{~min}$ at room temperature. Next, $100 \mu$ l equilibration buffer was added to the sections for $10 \mathrm{~min}$ at room temperature and sections were subsequently incubated with $\mathrm{TdT}$ reaction mix for $60 \mathrm{~min}$ at $37^{\circ} \mathrm{C}$ in the dark to label nuclear DNA fragmentation. Sections were immersed in $2 \mathrm{X} \mathrm{SSC}$ for $15 \mathrm{~min}$ at room temperature to stop the reaction. Cell nuclei were counterstained with DAPI $(1: 1,000$; cat. no. D1306; Thermo Fisher Scientific, Inc.) for $5 \mathrm{~min}$ at room temperature and mounted with VECTASHIELD ${ }^{\circledR}$ antifade mounting medium (Vector Laboratories, Inc.; Maravai LifeSciences). TUNEL-positive cells were observed under a fluorescent microscope at x20 magnification and the number of crypts and crypt-villus units were counted.

Dissection of interscapular brown adipose tissue (iBAT), epididymal white adipose tissue (eWAT) and inguinal white adipose tissue (iWAT). Following euthanasia of the mice and removal of the skin, iWAT in the inguinal triangular area, iBAT pads, which are located near the shoulder blades, and eWAT pads, which are attached to the gonads, were detached, weighed and snap frozen in liquid nitrogen.

Isolation and culture of primary intestinal crypts. Small intestines and colons were removed and opened longitudinally. Next, the tissues were washed 4-5 times with ice-cold PBS until they were clean, the villi of the small intestine were scraped off, and the small intestine and colons were sectioned into 5-mm sections $(12,13)$. Tissue fragments were subsequently transferred to Hank's balanced salt solution without calcium and magnesium, containing $0.5 \mathrm{mM}$ dithiothreitol and $8 \mathrm{mM}$ EDTA, and incubated on ice for 30-60 min. Intestinal crypts were mechanically released from the lamina propria by vigorous pipetting. The supernatants containing the crypts were filtered through a $70-\mu \mathrm{m}$ mesh and centrifuged at $100 \mathrm{x} \mathrm{g}$ for $5 \mathrm{~min}$ at $4^{\circ} \mathrm{C}$. Isolated crypts were counted and embedded in Matrigel (Corning, Inc.) on ice at $\sim 10$ crypts per $\mu 1$. Matrigel beads occupying the center of the well were constructed using $20 \mu \mathrm{l}$ of Matrigel to form a solid dome-like structure in a 24-well plate, and were subsequently overlaid with $500 \mu \mathrm{l}$ Advanced DMEM/F12 with HEPES (Gibco; Thermo Fisher Scientific, Inc.) containing $1 \mathrm{X}$ N-2 Supplement (Thermo Fisher Scientific, Inc.), B27 1x (Thermo Fisher Scientific, Inc.), 1X GlutaMAX $^{\text {тм }}$ Supplement (Gibco; Thermo Fisher Scientific, Inc.), $1 \mu \mathrm{M}$ N-acetyl-1-cysteine (Sigma-Aldrich; Merck $\mathrm{KGaA}$ ), $100 \mathrm{U} / \mathrm{ml}$ penicillin, $100 \mu \mathrm{g} / \mathrm{ml}$ streptomycin (Gibco; Thermo Fisher Scientific, Inc.), 50 ng/ml EGF (PeproTech, Inc.), $1 \mu \mathrm{g} / \mathrm{ml} \mathrm{R}$-spondin-1 (PeproTech, Inc.) and $100 \mathrm{ng} / \mathrm{ml}$ Noggin (PeproTech, Inc.) (14-16). Colonic crypts were cultured with an additional $100 \mathrm{ng} / \mathrm{ml}$ Wnt-3a (PeproTech, Inc.) (17).
Primary intestinal crypts were incubated in a fully humidified culture chamber with $5 \% \mathrm{CO}_{2}$ at $37^{\circ} \mathrm{C}$. The culture medium was changed every $48 \mathrm{~h}$, and the organoid-forming efficiency was calculated on days 4 and 6 .

Organoid immunofluorescence staining. Organoids embedded in Matrigel were fixed with $2 \%$ paraformaldehyde and $1 \%$ glutaraldehyde for $30 \mathrm{~min}$ at room temperature, and the fixed Matrigel was then placed in $20 \%$ sucrose overnight at $4^{\circ} \mathrm{C}$. Subsequently, the Matrigel domes were collected into O.C.T. compound (Sakura Finetek USA, Inc.), snap frozen and cryosectioned into $10-\mu \mathrm{m}$ sections. The sections were then incubated for 15 -min in $0.2 \mathrm{M}$ glycine solution at room temperature to quench the aldehyde groups. In order to permeabilize the slices, they were placed in $0.15 \%$ Triton X-100 for 15 min at room temperature. Next, the slices were incubated with an anti-lysozyme antibody (1:200; Abcam; cat. no. ab108508) overnight at $4^{\circ} \mathrm{C}$, followed by secondary $\mathrm{Cy}^{\mathrm{TM}} 3$-conjugated goat anti-rabbit IgG H\&L antibody, as described earlier. Organoids were counterstained with DAPI for $5 \mathrm{~min}$ at room temperature and visualized using an epi-fluorescence microscope. Images were obtained at x40 or x100 magnification.

Fluorescence-activated cell sorting (FACs). Intestinal crypts and villi were isolated by EDTA chelation buffer treatment, as described earlier. The cell suspensions, composed of crypts and villi in the small intestine, which houses a single cell layer of epithelium from the submucosa, were dissociated into single cells using TrypLE Express (Gibco; Thermo Fisher Scientific, Inc.), and the cells were passed through $40-\mu \mathrm{m}$ filters. Cells were fixed in 1X intracellular fixation buffer (cat. no. 00-8222; eBioscience; Thermo Fisher Scientific, Inc.) for $30 \mathrm{~min}$ at $4^{\circ} \mathrm{C}$ and subsequently washed in $1 \mathrm{X}$ permeabilization buffer (cat. no. 00-8333; eBioscience; Thermo Fisher Scientific, Inc.) for $10 \mathrm{~min}$ at $4^{\circ} \mathrm{C}$. Cells were blocked at $4^{\circ} \mathrm{C}$ for $30 \mathrm{~min}$ in $0.5 \%$ BSA (cat. no. 4240GR100; neoFroxx)/PBS blocking solution and subsequently incubated with antibodies against surface markers at $4^{\circ} \mathrm{C}$ for $30 \mathrm{~min}$ : Allophycocyanin (APC)-conjugated Lgr5/GPR49 (0.5 $\mu \mathrm{g} / 10^{6}$ cells; R\&D Systems, Inc.; cat. no. FAB82401A), phycoerythrin (PE)-conjugated CD24 (1:200; BD Biosciences; cat. no. 553262), PE-conjugated mucin 2 (Muc2; 1:200; Santa Cruz Biotechnology, Inc.; cat. no. sc-515032), and FITC-conjugated CD326 (EpCAM) antibodies $\left(0.125 \mu \mathrm{g} / 10^{6}\right.$ cells; eBioscience; Thermo Fisher Scientific, Inc.; cat. no. 14-5791-81). Apoptosis was detected using propidium iodide (cat. no. BMS500PI; eBioscience; Thermo Fisher Scientific, Inc.), according to the manufacturer's protocol. A BD FACSAria II SORP cell sorter (BD Biosciences) was used to isolate different types of cells: ISCs were isolated as $\mathrm{Lgr}^{\mathrm{hi}} \mathrm{Epcam}^{+}$cells, progenitor cells were isolated as $\mathrm{Lgr}^{\text {low}} \mathrm{Epcam}^{+}$, Paneth cells were isolated as CD24 ${ }^{\text {hi }}$ Sidescatter ${ }^{\text {hi Epcam }}{ }^{+}$and goblet cells were isolated as Muc2 ${ }^{\text {hi }}$ Epcam $^{+}$cells (18). Data analysis was performed using FlowJo software (version 10; Tree Star, Inc.). All RT-qPCR experiments were repeated $\geq 2$ times.

Reverse transcription-quantitative polymerase chain reaction $(R T-q P C R)$. Total RNA was isolated from eWAT and intestinal tissues using TRIzol ${ }^{\circledR}$ reagent (Invitrogen; Thermo Fisher Scientific, Inc.), according to the manufacturer's 

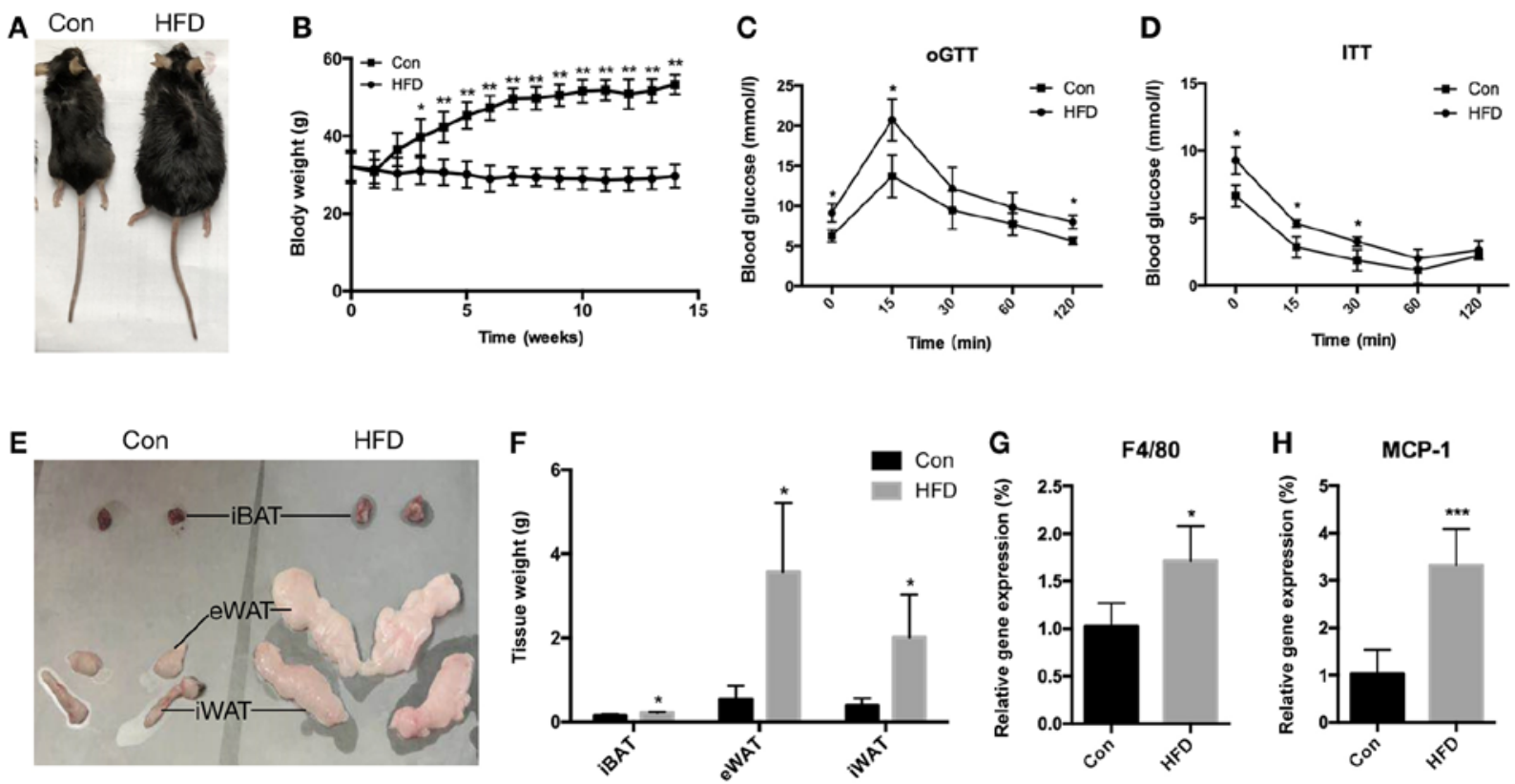

Figure 1. Characteristics of middle-aged (12-month-old) female C57BL/6 mice fed an HFD for 14-weeks. (A) Representative appearance of Con and HFD mice. (B) Body weights were determined weekly. (C) oGTT and (D) ITT results. (E) Representative images of iBAT, eWAT and iWAT. (F) Tissue weight of iBAT, eWAT and iWAT from the two mouse groups. mRNA expression levels of (G) F4/80 and (H) MCP-1 inflammation-associated genes in eWAT. Data are presented as the mean \pm standard deviation. ${ }^{*} \mathrm{P}<0.05,{ }^{* *} \mathrm{P}<0.01$ and ${ }^{* * * *} \mathrm{P}<0.001$, vs. Con group. HFD, high-fat diet; Con, control; oGTT, oral glucose tolerance test; ITT, insulin tolerance test; iBAT, interscapular brown adipose tissue; eWAT, epididymal white adipose tissue; iWAT, inguinal white adipose tissue.

protocol, and the RNA concentration was measured at 260 and $280 \mathrm{~nm}$ using a NanoDrop spectrophotometer (Thermo Fisher Scientific, Inc.). Total RNA samples $(2 \mu \mathrm{g})$ were then reverse transcribed into cDNA using $200 \mathrm{U}$ M-MLV Reverse Transcriptase (Promega Corporation) in the presence of $0.5 \mathrm{mM}$ deoxynucleotide triphosphate, $25 \mathrm{U}$ RNase inhibitor and $10 \mathrm{mM}$ random hexamer primers (Promega Corporation), with a final volume of $25 \mu 1$. Samples were incubated at $37^{\circ} \mathrm{C}$ for $1 \mathrm{~h}, 95^{\circ} \mathrm{C}$ for $5 \mathrm{~min}$ and then placed in an ice water mixture for 5 min. qPCR was subsequently performed in triplicate using SYBR ${ }^{\circledR}$ Green Real-Time PCR Master mix (Roche Diagnostics) at a final volume of $25 \mu 1$, using an ABI 7000 StepOnePlus Real-Time PCR system (Thermo Fisher Scientific, Inc.). The PCR thermal cycling conditions were as follows: $10 \mathrm{~min}$ at $95^{\circ} \mathrm{C} ; 40$ cycles of $15 \mathrm{sec}$ at $95^{\circ} \mathrm{C}$ and $60 \mathrm{sec}$ at $60^{\circ} \mathrm{C}$. The temperature was increased from $60^{\circ} \mathrm{C}$ to $95^{\circ} \mathrm{C}$, and the PCR melting curve was plotted at every $1^{\circ} \mathrm{C}$ following the amplification step. The PCR primers were designed using Primer 5 software (Premier Biosoft) and are presented in Table SI. Expression levels were normalized to $\beta$-actin. The mean value of triplicate analyses for each sample was calculated and expressed as the quantification cycle threshold $(\mathrm{Cq})$. Gene expression was then calculated as the $\Delta \mathrm{Cq}$, defined as the difference between the $\mathrm{Cq}$ value of the sample and the $\mathrm{Cq}$ value of $\beta$-actin, which was used as an internal reference. Finally, the relative expression levels were determined using the comparative $2^{-\Delta \Delta \mathrm{Cq}}$ method (19).

Statistical analysis. All the data were analyzed with Microsoft Excel (version 16.16.13; Microsoft Corporation) and GraphPad Prism (version 6.0c; GraphPad Software, Inc.) software and the data was presented as the mean \pm SD. RT-qPCR experiments were repeated $\geq 2$ times, whereas 3 mice/group were analyzed in the FACS assay, which was repeated once. For histological analysis, including TUNEL, 30-40 crypt-villus units in the small intestine/section and 30-40 crypts in the colon/section were observed and assessed in a single experiment. For organoid assays, 5-6 wells/group with 2-3 different mice were analyzed in a single experiment. Statistical significance was calculated using Student's t-test. $\mathrm{P}<0.05$ was considered to indicate a statistically significant difference.

\section{Results}

Characteristics of the HFD-fed mice. In the present study, 12-month old C57BL/6J female mice were fed an HFD for 14 weeks to establish an HFD-induced obese mouse model (Fig. 1A). Metabolic assessments were performed on the mice, which indicated that they developed metabolic abnormalities. Mice fed an HFD had a significantly increased body weight (Fig. 1B) after 14 weeks of the HFD $(\mathrm{P}<0.01)$, while they were glucose intolerant (Fig. 1C) and insulin resistant (Fig. 1D) compared with the mice fed a normal chow diet. In addition, the fat weight of the iBAT $(\mathrm{P}<0.05)$, eWAT $(\mathrm{P}<0.05)$ and iWAT $(\mathrm{P}<0.05)$ increased significantly in the HFD mice (Fig. 1E and F). Furthermore, the mRNA expression levels of the inflammatory factors F4/80 $(\mathrm{P}<0.05)$ and monocyte chemoattractant protein-1 (MCP-1; $\mathrm{P}<0.001)$ were found to be upregulated in the eWAT of the HFD mice (Fig. $1 \mathrm{G}$ and $\mathrm{H}$ ). These results demonstrated that certain physiological characteristics were altered in the HFD mice and thus, an obese mouse model was successfully generated.

HFD alters the intestinal morphology. In order to elucidate the effect of HFD on intestinal function, the overall appearance of 


\section{Small intestine}

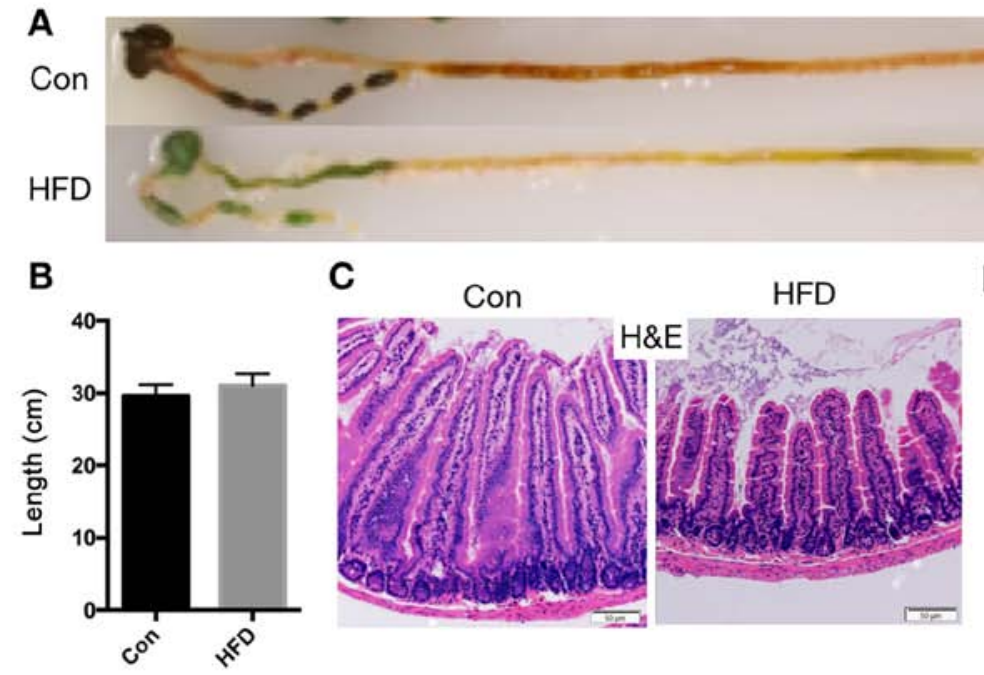

\section{Colon}
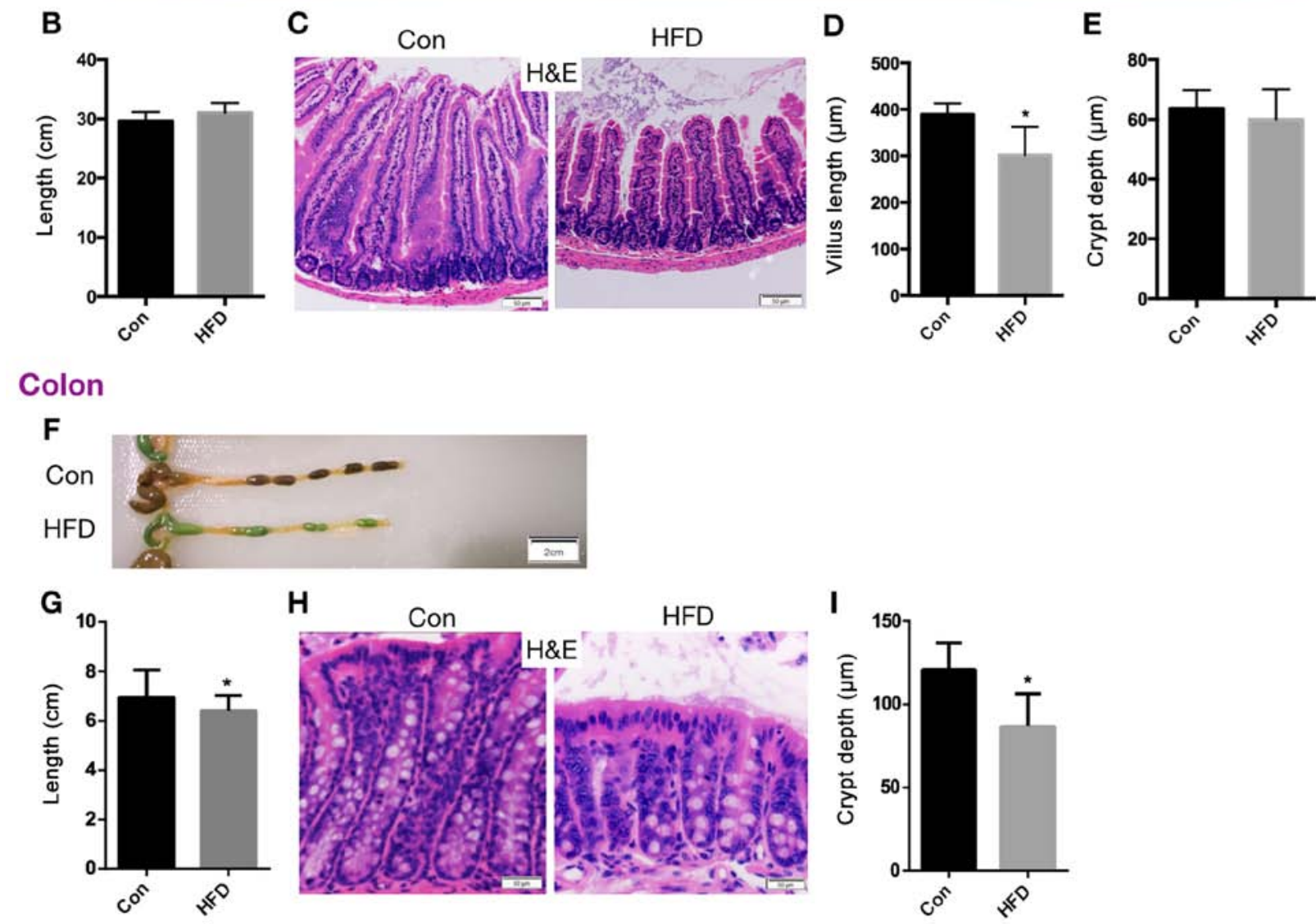

Figure 2. HFD alters the intestinal morphology. Mice were fed an HFD for 14-weeks, and then the small intestines and colons were removed. (A) Representative images (scale bar, $2 \mathrm{~cm}$ ), and (B) quantified length of the small intestine. (C) Representative H\&E staining images of the crypt and villi in the jejunum (scale bar, $50 \mu \mathrm{m}$; magnification, $\mathrm{x} 40$ ). (D) Villus length and (E) crypt depth in the small intestine. (F) Representative images of the colon of mice in the two groups (scale bar, $2 \mathrm{~cm}$ ), and (G) quantified colon length. (H) H\&E staining images of colonic crypt (scale bar, $50 \mu \mathrm{m}$; magnification, $\mathrm{x} 40$ ), and (I) quantified colonic crypt depth. Data are presented as the mean \pm standard deviation. ${ }^{*} \mathrm{P}<0.05$ vs. Con group. HFD, high-fat diet; Con, control; H\&E, hematoxylin and eosin.

the intestine was first evaluated. The length of the small intestine was not significantly altered in the HFD mice (Fig. 2A and B). $H \& E$ staining was used to analyze the intestinal tissue and to quantify the length of the intestinal villi and the depth of intestinal crypts. In the small intestine, the results revealed that the length of villi in the HFD group was significantly shorter compared with that in the control group ( $\mathrm{P}<0.05$; Fig. $2 \mathrm{C}$ and $\mathrm{D})$, although the crypt depth was not evidently altered (Fig. 2E). In the colon, the length was significantly reduced $(\mathrm{P}<0.05$; Fig. $2 \mathrm{~F}$ and $\mathrm{G})$ and the depth of the crypts was significantly shorter in the HFD mice compared with the control group $(\mathrm{P}<0.05$; Fig. $2 \mathrm{H}$ and $\mathrm{I})$. These data suggest that the intestinal morphology was evidently altered in mice fed an HFD, and thus the intestinal function may also be altered by this diet.

HFD increases the ISC count and alters crypt function in the small intestine. To determine the effects of HFD on ISCs, flow cytometry was performed to count Lgr5-high ISCs and
Lgr5-low progenitor cells in the small intestine. Mice fed an HFD had a significantly increased number of ISCs $(\mathrm{P}<0.05)$ and progenitor cells $(\mathrm{P}<0.0001)$ in the epithelium of the small intestine when compared with the control group (Fig. 3A-C). The mRNA expression of Lgr5 in small intestine epithelial tissues was also measured, and it was revealed that the HFD increased Lgr5 mRNA levels compared with the control group $(\mathrm{P}<0.05$; Fig. 3D).

As the ISC counts increased in the HFD mice, the effect of HFD on regeneration was also assessed. Using an in vitro approach, the potential of intestinal crypts to form multipotent, self-renewing intestinal organoids was investigated. For this, small intestinal crypts were isolated from the control and HFD mice, and were cultured in Matrigel to develop organoid colonies (Fig. 3E). Compared with the control group, the proportion of small intestinal crypts that grew into intestinal organoids was significantly higher in the crypts obtained from the HFD mice compared with the control mice after 4 days of culture $(\mathrm{P}<0.05$; 

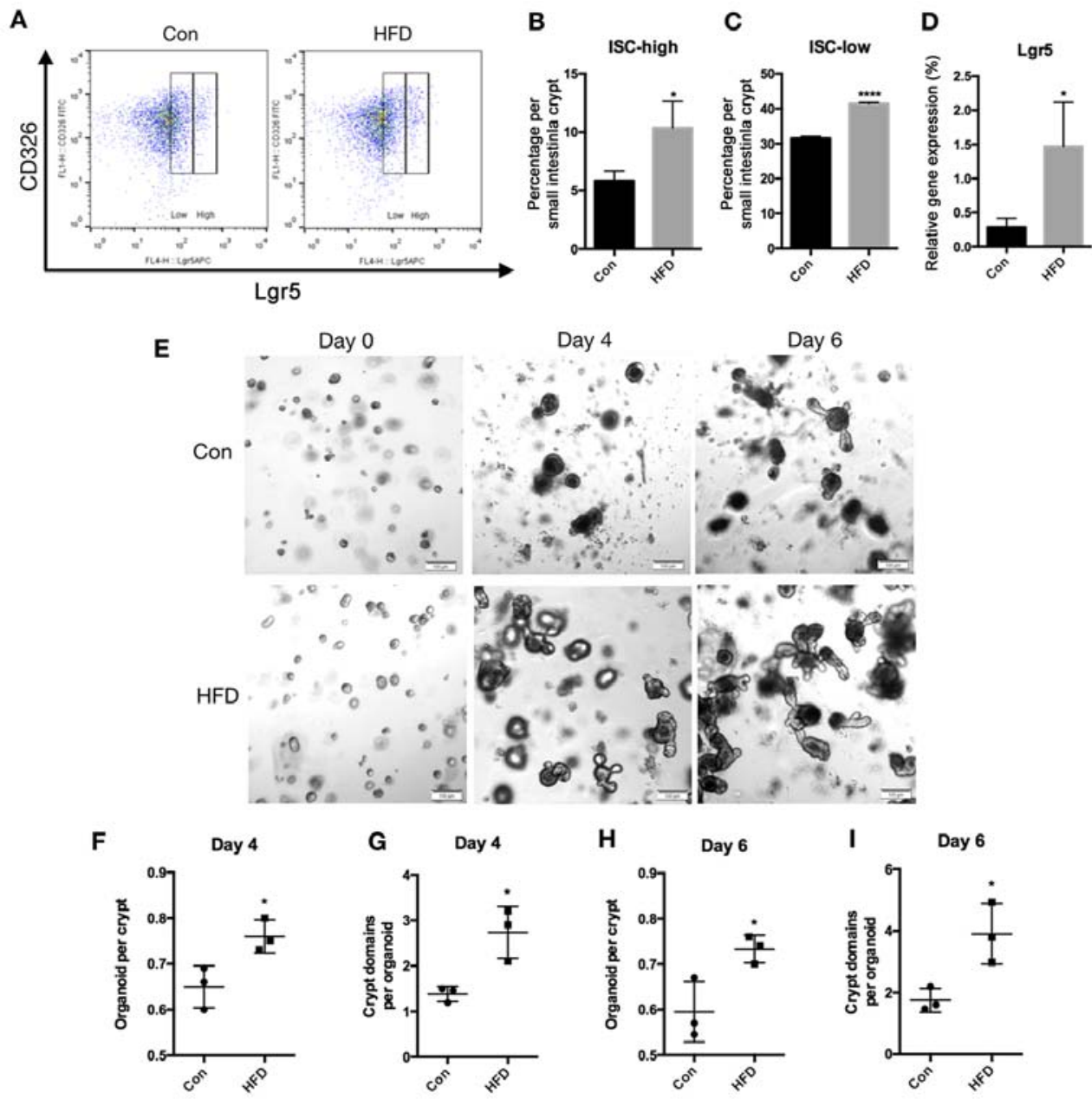

Figure 3. An HFD increases the ISC count and crypt function in the small intestine of mice. Small intestinal crypts and villi were isolated and epithelial cell suspensions were dissociated into single cells. (A) Representative flow cytometry analysis showing Lgr 5 expression in the CD326 cell population obtained from the small intestine. (B) ISCs defined as $\mathrm{Lgr} 5^{\text {high }}$, and (C) progenitor cells defined as Lgr $5^{\text {low }}$ in the entire small intestine. (D) mRNA expression of Lgr5 in the small intestine. (E) Small intestinal crypts were isolated and cultured in Matrigel to develop organoid colonies. Representative images of small intestinal organoids at days 0,4 and 6 are displayed (scale bar, $100 \mu \mathrm{m}$; magnification, x20). (F) Organoids formed per crypt and (G) crypt-domains per organoid on day 4. (H) Organoids formed per crypt and (I) crypt-domains per organoid on day 6. Data are presented as the mean \pm standard deviation. " $\mathrm{P}<0.05$ and ${ }^{* * * * *} \mathrm{P}<0.0001$, vs. Con group. HFD, high-fat diet; ISC, intestinal stem cell; Con, control.

Fig. 3F). The number of crypt-domains per organoid at day 4 were also increased in the crypts obtained from the HFD mice (P<0.05; Fig. 3G). At day 6, the results also demonstrated that the proportion of small intestinal crypts growing into intestinal organoids and the crypt-domains per organoid were both increased in the crypts obtained from the HFD mice $(\mathrm{P}<0.05$; Fig. $3 \mathrm{H}$ and I). Taken together, an HFD resulted in an increase in ISC counts, and HFD-derived crypts were more likely to form mini-intestine organoids in a 3D culture.

HFD increases the ISC count but does not affect crypt function in the colon. In the colon, flow cytometry revealed that the proportion of Lgr5-high ISCs increased in the HFD mice $(\mathrm{P}<0.05$; Fig. 4A and $\mathrm{B})$, whereas the percentage of Lgr5-low progenitor cells remained the same (Fig. 4A and C). Using immunofluorescence staining, it was demonstrated that the expression of Lgr5 in colon epithelial tissues was upregulated in the HFD mice $(\mathrm{P}<0.05$; Fig. 4D-F). It was also observed that the mRNA levels of Lgr5 $(\mathrm{P}<0.01)$ in the colonic epithelial tissues of HFD mice were significantly upregulated compared with those in control mice (Fig. 4G). Furthermore, immuno- histochemical staining for Ki67, an ISC marker, indicated that the expression of Ki67 was upregulated in the HFD mice $(\mathrm{P}<0.05$; Fig. $4 \mathrm{H}$ and $\mathrm{I})$, while a similar change was observed in the mRNA level of Ki67 (P<0.01; Fig. 4J).

Intestinal organoids derived from colon crypts tend to remain spherical and undifferentiated due to the addition of Wnt3a to the culture medium, which is essential for maintaining ISCs (20). In the present study, an HFD did not affect the growth of colonic crypts into organoids by day 4 (Fig. 4K and L) or day 6 (Fig. 4K and M). These data support the notion that an HFD only increased the count of ISCs in the colon but had no effect on crypt function.

Barrier function of the small intestine is not affected by $H F D$. To determine whether the barrier function of the small intestine was affected by HFD, flow cytometry analysis was used to analyze the proportion and number of IECs, particularly goblet and Paneth cells. The results revealed that there were no marked changes in the proportion of goblet cells in the HFD mice (Fig. 5A and B). No significant difference in the number of goblet cells in single crypts, determined by PAS 

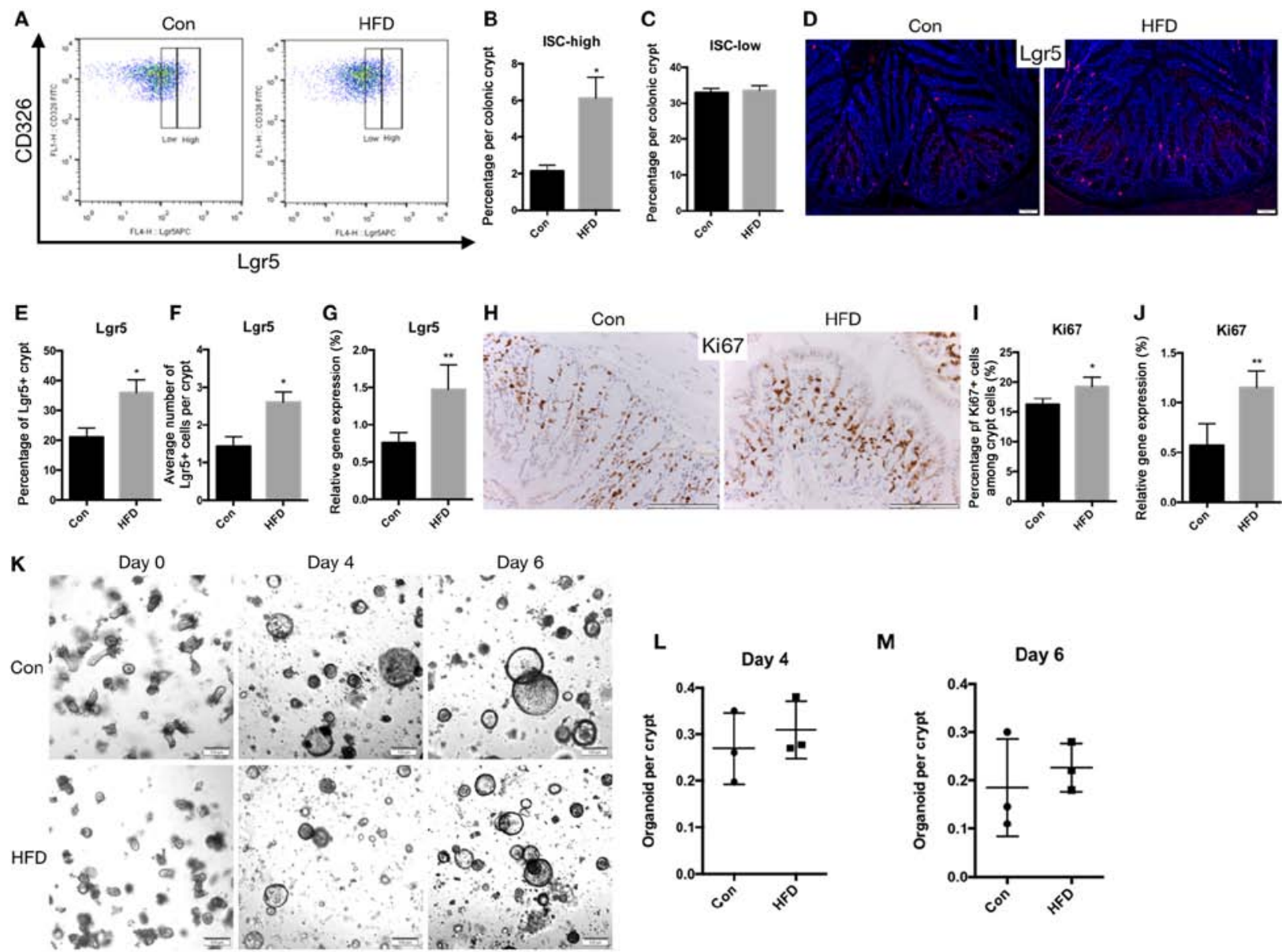

Figure 4. An HFD increases ISC count in the colon. Colon crypts were isolated, and epithelial cell suspensions were dissociated into single cells (A) Representative flow cytometry analysis showing Lgr5 expression in the CD326 cell population obtained from the colon. (B) ISCs defined as Lgr5 ${ }^{\text {high }}$, and (C) progenitor cells defined as Lgr5 ${ }^{\text {low }}$ in the entire colon. (D) Representative images of immunofluorescence staining for Lgr5, seen as red fluorescence, with DAPI used as a counterstain (scale bar, $50 \mu \mathrm{m}$; magnification, $\mathrm{x} 40$ ). (E) Percentage of Lgr $5^{+}$cells among the crypt cells, and (F) the number of Lgr5 ${ }^{+}$cells per a crypt. (G) mRNA expression of Lgr5. (H) Representative images of immunohistochemical staining for Ki67 (scale bar, $100 \mu$ m; magnification, x100), and (I) quantified $\mathrm{Ki}^{+} 7^{+}$cells as a percentage of the crypt cells. (J) mRNA expression of Ki67 in the colon. (K) Colon crypts were isolated from Con and HFD mice and cultured in Matrigel to develop organoid colonies. Representative images of colonic organoids at days 0,4 and 6 are displayed (scale bar, $100 \mu$ m; magnification, $\mathrm{x} 20)$. Organoids per crypt at $(\mathrm{L})$ day 4 and $(\mathrm{M})$ day 6 are shown. Data are presented as the mean \pm standard deviation. ${ }^{*} \mathrm{P}<0.05$ and ${ }^{* * *} \mathrm{P}<0.01$, vs. Con group. ISC, intestinal stem cell; HFD, high-fat diet; Con, control.

staining, were observed in the HFD group compared with the control group (Fig. 5C-E). Similarly, the proportion of Paneth cells was not affected by the HFD (Fig. 5F and G), and the number of Paneth cells in the small intestinal crypt derived from organoids did not differ significantly between the HFD and control mice (Fig. 5H and I).

It is known that the secretion of highly glycosylated mucins into the intestinal lumen by goblet cells creates the first line of defense against microbial encroachment (21). In the present study, the mRNA expression levels of Muc2 in the small intestine tissues did not significantly differ in the HFD group compared with the control mice, as determined by RT-qPCR (Fig. 5J).

The rate of apoptosis of IECs was then determined by conducting a TUNEL assay. The results demonstrated no significant difference in the apoptosis rate between the HFD and control mice (Fig. 6A-C). Furthermore, immunohistochemical staining for P21 (Fig. 6D-F) and P53 (Fig. 6G-I), which are apoptosis-marker genes, was not significantly altered by the HFD. Additionally, consistent results were obtained for the mRNA expression levels of P21 and P53 (Fig. 6J and K). These results suggested that the small intestine barrier between the host and the internal environment was not affected by the HFD.

HFD compromises the intestinal barrier function. To determine the effect of an HFD on the barrier function of the colon, flow cytometry analysis was also used to analyze the proportion and number of goblet cells in the colon. The results revealed that the proportion of goblet cells amongst colonic epithelial cells was significantly lower in the HFD group compared with that in the control group $(\mathrm{P}<0.01$; Fig. $7 \mathrm{~A}$ and $\mathrm{B})$. Using PAS staining, it was demonstrated that the number of goblet cells was also decreased $(\mathrm{P}<0.05$; Fig. $7 \mathrm{C}-\mathrm{E})$. Muc2 is the most abundant mucin produced by goblet cells and serves an essential role in the organization of the intestinal mucous layers at the epithelial surface of the colon (22). Therefore, the mRNA expression levels of Muc2 were assessed, and it was observed that Muc2 levels were significantly decreased in the HFD mice compared with the control mice $(\mathrm{P}<0.001$; Fig. $7 \mathrm{~F})$. These data 


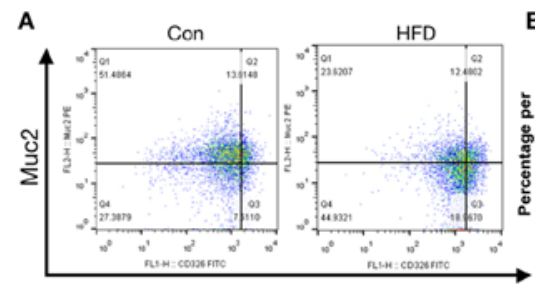
B Goblet cell
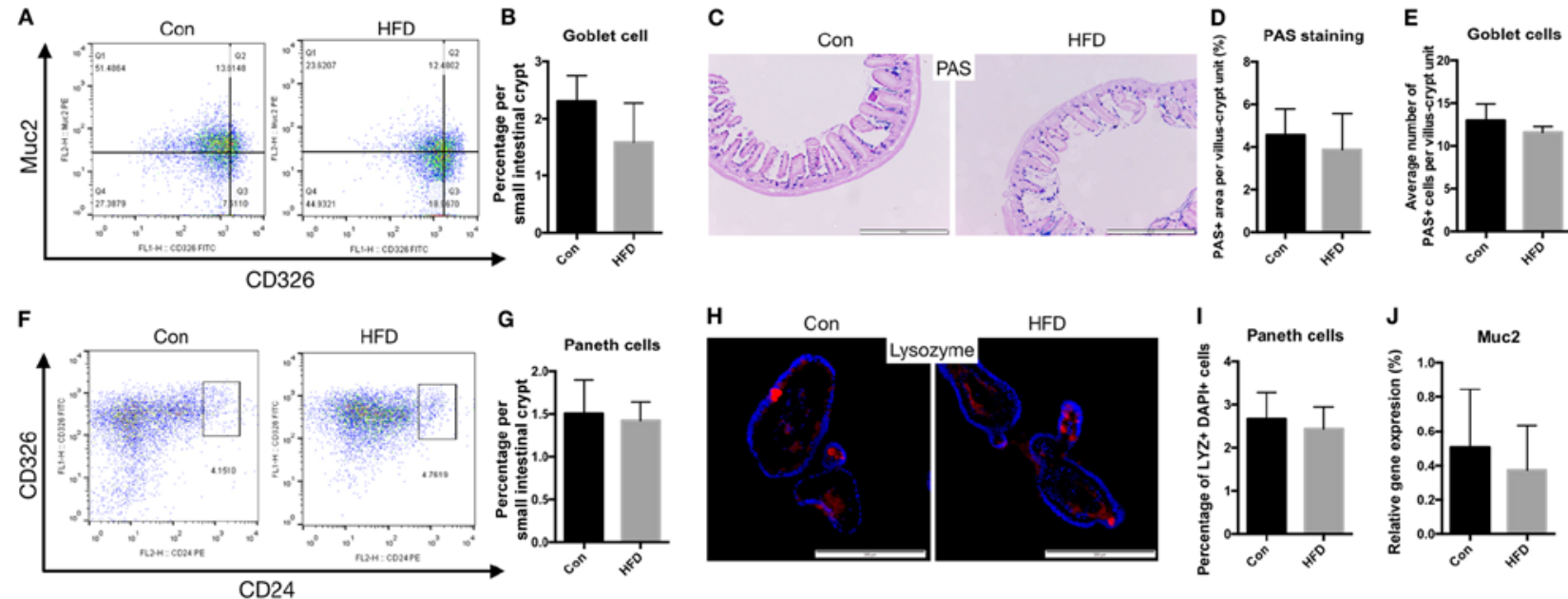

Figure 5. Barrier function of the small intestine was not affected by HFD. Goblet and Paneth cell numbers, and cell apoptosis were analyzed to determine the barrier function of the small intestine. (A) Representative flow cytometry analysis of Muc2 expression in CD326 cell populations. (B) Percentage of goblet cells in the small intestine. (C) Ileal sections were stained for goblet cells using PAS (scale bar, $500 \mu \mathrm{m}$; magnification, x20). (D) Percentage of area stained as PAS-positive among the total villi-crypts sections. (E) Quantification of the number of goblet cells per villus-crypt unit. (F) Representative flow cytometry analysis showing CD24 expression in CD326 cell populations. (G) Percentage of Paneth cells in small intestinal crypts. (H) Crypt-derived organoids of Paneth cells, including lysozyme-positive cells, assessed using immunofluorescence (blue, DAPI; red, lysozyme; scale bar, $200 \mu \mathrm{m}$; magnification, x40). (I) Quantification of Paneth cells in small intestinal crypt-derived organoids. (J) mRNA expression levels of Muc2 in the small intestine of the Con and HFD mice. HFD, high-fat diet; Con, control; PAS, Periodic Acid-Schiff; Muc2, mucin 2.

A

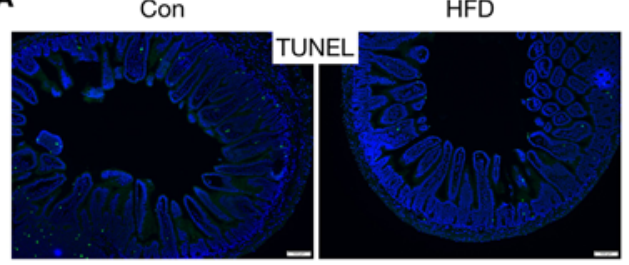

D

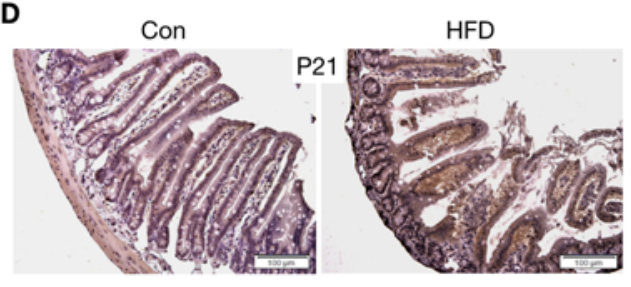

G

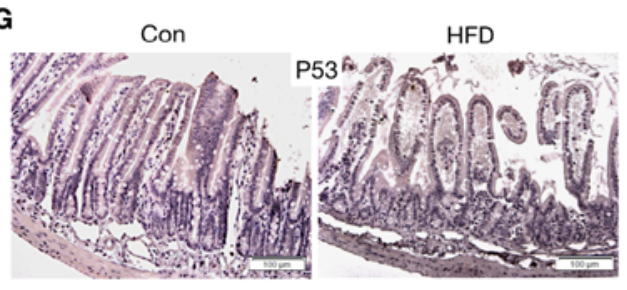

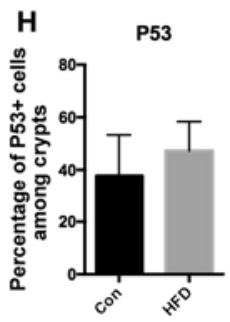
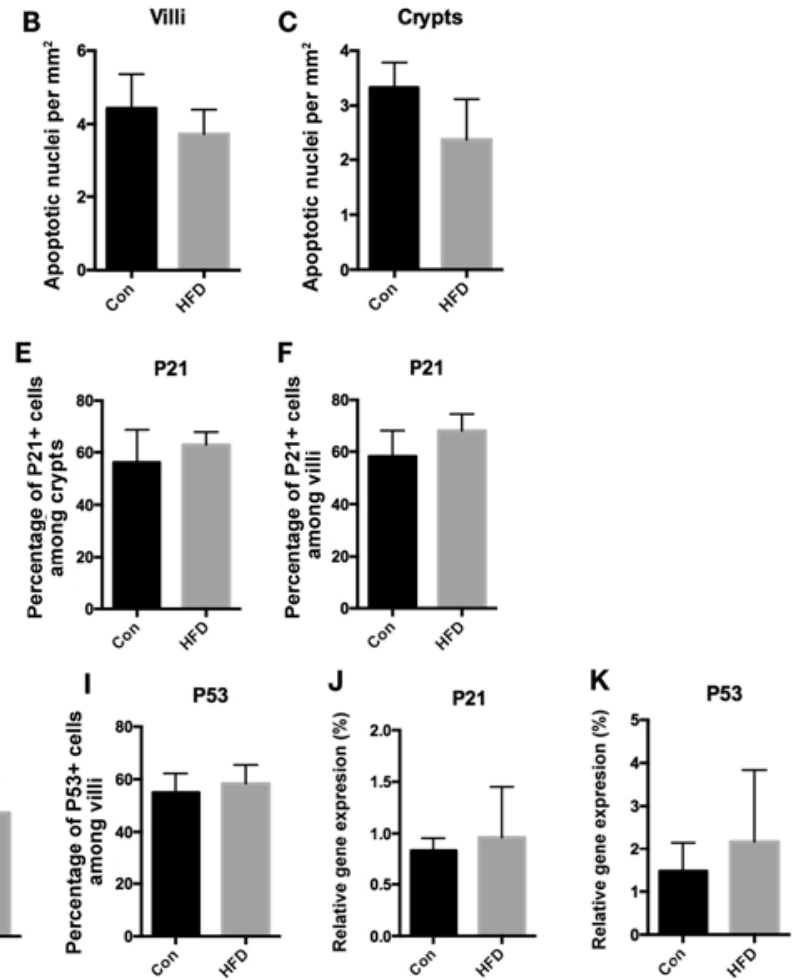

Figure 6. Cell apoptosis in the small intestine was not affected by HFD. (A) Ileal sections stained for apoptotic cells (scale bar, $100 \mu \mathrm{m}$; magnification, x20), Quantification of apoptotic cells among (B) villi and (C) crypt sections. (D) Expression of P21 in the small intestine, examined using immunohistochemistry (scale bars, $100 \mu \mathrm{m}$; magnification, $\mathrm{x} 40$ ). Quantification of P21 positive cells as a percentage of the (E) crypts and (F) villi. (G) Immunohistochemical assay for P53 in the small intestine (scale bars, $100 \mu \mathrm{m}$; magnification, x40). Quantification of P53 positive cells as a percentage of the (H) crypts and (I) villi. (J) P21 and (K) P53 mRNA expression levels in the small intestine. Data are presented as the mean \pm standard deviation. HFD, high-fat diet; Con, control.

suggest that an HFD results in damage to the IEC secretory function.

Below the mucous layers, IECs form a continuous physical barrier $(21,23)$. Tight junctions connect adjacent
IECs and are associated with intestinal permeability (24). Disruption of barrier function is characterized by defects in epithelial tight-junction-associated proteins, such as ZO-1 and Claudin-2 (25). In the current study, PAS staining 
A

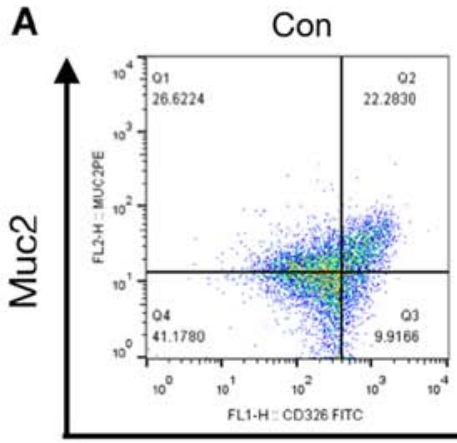

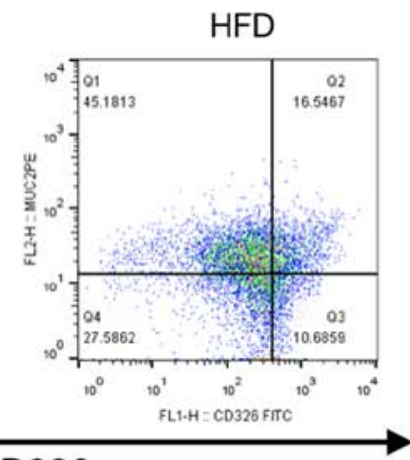

CD326

C

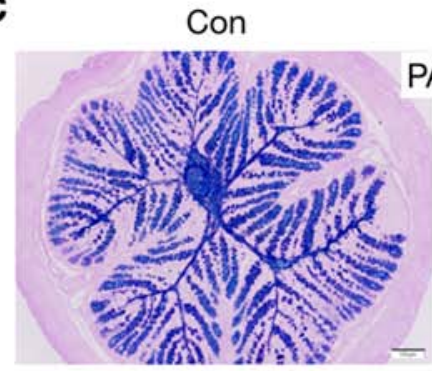

HFD

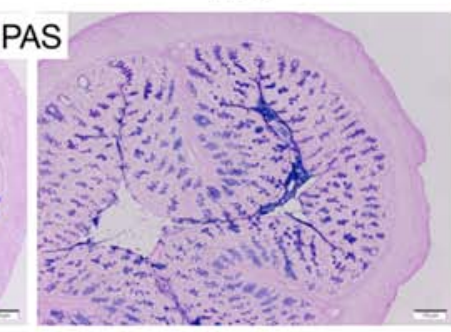

G

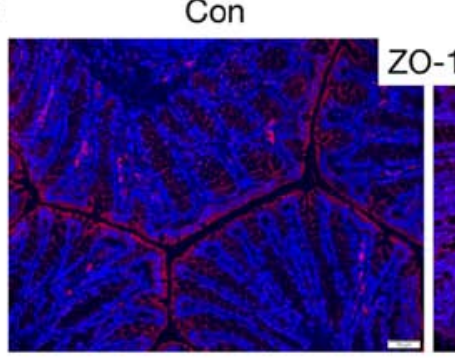

HFD

I

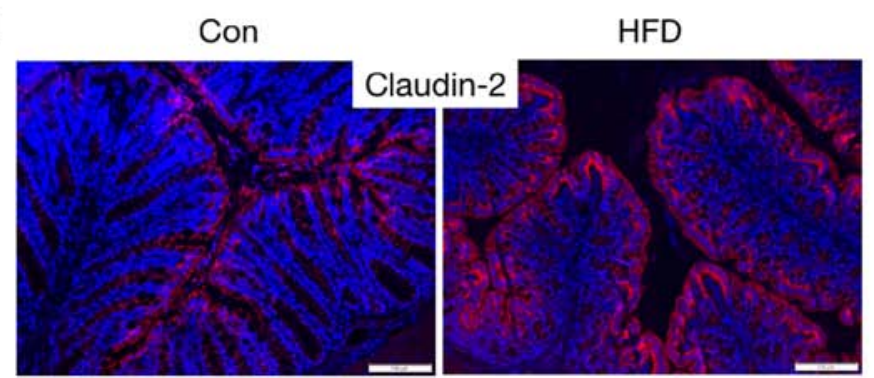

Muc2

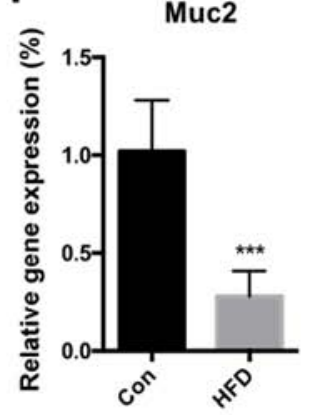

Con
B
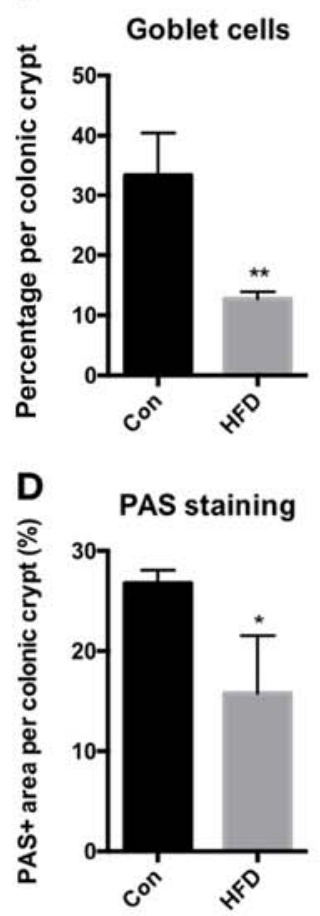

HFD
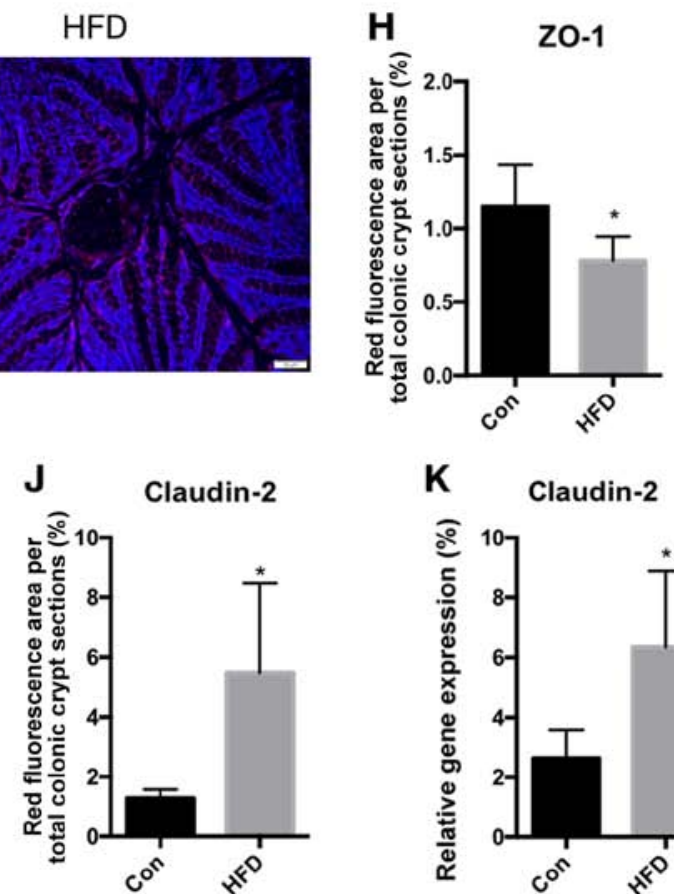

E

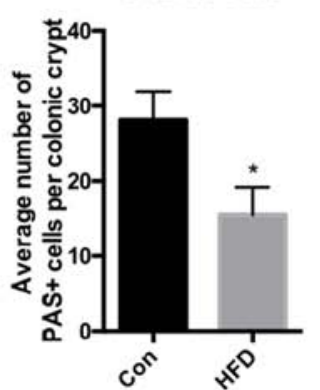

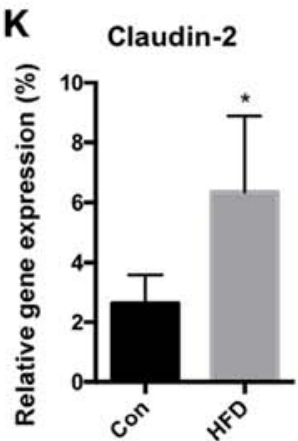

Figure 7. An HFD compromises the barrier function of the colon. Goblet cell number, tight junctions and cell apoptosis were analyzed to determine the barrier function of the colon. (A) Representative flow cytometry analysis, showing Muc2 expression among the CD326 cell populations. (B) Proportion of goblet cells. (C) Histochemical PAS staining of goblet cells (scale bar, $100 \mu \mathrm{m}$; magnification, x20), (D) percentage of area stained as PAS-positive among the colonic crypts, and (E) quantification of the average number of goblet cells per crypt. (F) mRNA expression of Muc2 in the colon. (G) Representative images of immunofluorescence staining for ZO-1 seen as red fluorescence, with DAPI used as the counterstain (scale bar, $50 \mu \mathrm{m}$; magnification, $\mathrm{x} 40$ ), and (H) quantification of red fluorescence. (I) Representative images of immunofluorescence staining for Claudin-2 seen as red fluorescence, with DAPI used as the counterstain (scale bar, $100 \mu \mathrm{m}$; magnification, $\mathrm{x} 40)$, and $(\mathrm{J})$ quantification of red fluorescence. $(\mathrm{K}) \mathrm{mRNA}$ expression of $\mathrm{Claudin}-2$ in the colon. ${ }^{*} \mathrm{P}<0.05$, ${ }^{* *} \mathrm{P}<0.01$ and ${ }^{* * *} \mathrm{P}<0.001$, vs. Con group. HFD, high-fat diet; Con, control; PAS, Periodic Acid-Schiff; Muc2, mucin 2.

indicated that the expression of ZO-1 was downregulated in the HFD mice compared with the controls $(\mathrm{P}<0.05$; Fig. 7G and $\mathrm{H}$ ). However, the expression of Claudin-2 was significantly upregulated in the HFD mice $(\mathrm{P}<0.05$; Fig. 7I-K).
The rate of apoptosis in colonic epithelial cells may also influence the function of the colonic barrier. Therefore, the apoptotic rate of these cells was measured. The results revealed that the rate of apoptosis was increased in the HFD mice ( $\mathrm{P}<0.01$; Fig. $8 \mathrm{~A}$ and $\mathrm{B}$ ). In addition, immunohistochem- 

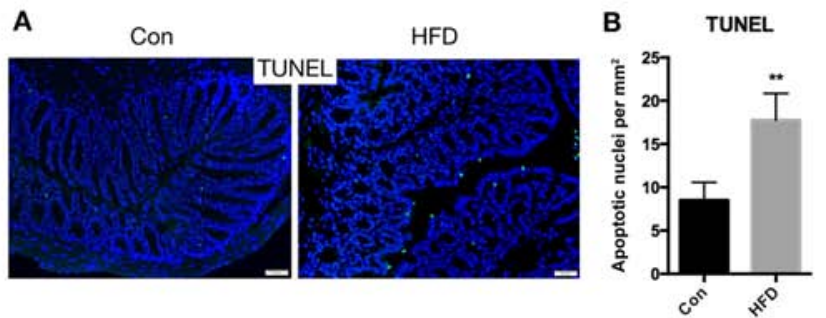

E

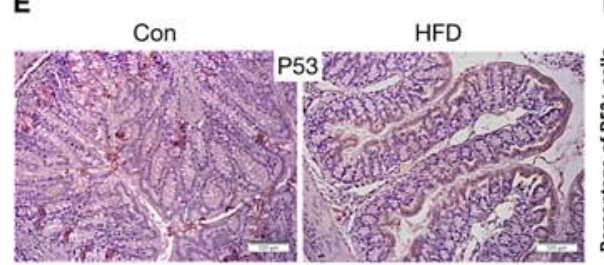

F

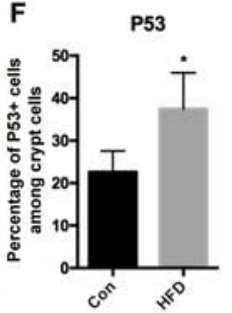

C
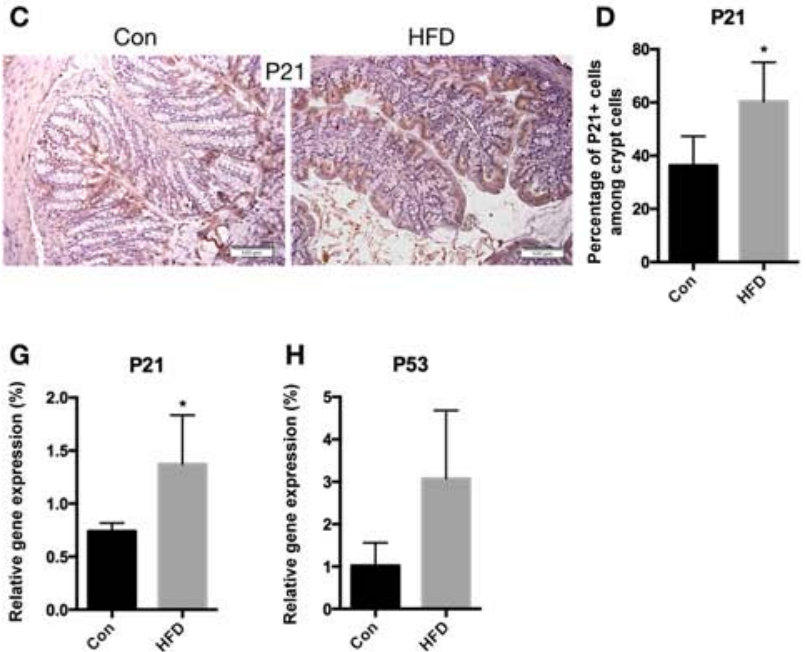

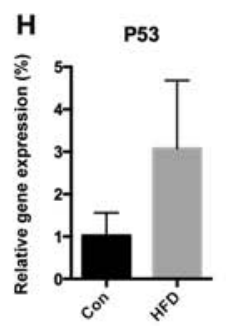

Figure 8. Increased apoptosis in the colon of HFD-fed mice. (A) Colon sections were stained for apoptotic cells using TUNEL assay (scale bar, $50 \mu$ m; magnification, x40), and (B) the quantified number of apoptotic cells is shown. (C) Immunohistochemical staining for P21 expression in the colon (scale bars, $100 \mu \mathrm{m}$; magnification, $\mathrm{x} 40$ ), and (D) quantified percentage of P21-positive crypt cells. (E) Representative images of immunohistochemical staining for P53 (scale bars, $100 \mu \mathrm{m}$; magnification, x40), and (F) quantified percentage of P53-positive crypt cells. (G) P21 and (H) P53 mRNA expression levels in the colon. Data are presented as the mean \pm standard deviation. ${ }^{*} \mathrm{P}<0.05$ and ${ }^{* *} \mathrm{P}<0.01$, vs. Con group. HFD, high-fat diet; Con, control.

ical staining for P21 (Fig. 8C and D) and P53 (Fig. 8E and F) demonstrated increasing expression of these genes in the HFD mice $(\mathrm{P}<0.05)$. The mRNA expression levels of $\mathrm{P} 21 \quad(\mathrm{P}<0.05)$ and P53 $(\mathrm{P}=0.0518)$ were also increased in the HFD mice, compared with the control mice (Fig. 8G and H). These findings suggest that an HFD results in increased apoptosis of IECs of the colon.

\section{Discussion}

As the intestine consumes a considerable amount of energy, modulating the intestinal volume and cellular architecture is an important adaptation to fluctuations in nutrient availability $(26,27)$. Several studies have reported that excess or reduced calorie consumption have profound implications on the physiology of the intestine. For instance, reduced calorie intake resulted in reduced overall mass of the small intestine in murine models, while increased calorie intake reversed these changes (28). Furthermore, overfeeding or consumption of an HFD stimulates proliferation of the intestinal epithelium (29). However, studies on the effects of an HFD on the morphology of the intestine, particularly the small intestine, are contradictory. Beyaz et al (18) reported that the small intestines of HFD-fed mice were shorter in length, and that an HFD also resulted in a mild reduction in villi length and an increase in crypt depth. However, other studies observed that the duodenal and jejunal crypt-villus height increased significantly in HFD-fed or db/db mice (29,30). These inconsistent results may be due to the differences in the animal models, such as the high-fat feeding time and age of the mice. In the present study, the villus length of small intestine, as well as the total length and crypt depth of the colon, decreased in the HFD-fed group. These morphological changes suggest an effect of HFD on the intestinal function.

An increasing number of epidemiological studies have indicated that obesity is associated with an elevated risk of several different types of cancer, particularly of gastrointes- tinal tract cancer (31-33). One of the primary drivers of the contribution of diet to cancer incidence is through alterations to the biology of ISCs. A previous study demonstrated that different dietary regimens and calorie restriction increased the stem cell numbers and regulated ISC function (34). By contrast, in the present study, an HFD increased the ISC counts, induced self-renewal and increased features associated with stemness (organoid-initiating capacity). Similar results were obtained in the study by Beyaz et al (18), in that an HFD enhanced the stemness and tumorigenicity of intestinal progenitor cells, suggesting that an HFD enhances regeneration. A recent study revealed that ISCs in females have greater proliferative ability as compared with those in males (35). The results of the present study indicated that female mice fed an HFD exhibited increased ISC counts, while crypts obtained from mice fed an HFD were more likely to form mini-intestine organoids in a 3D culture, which may partially account for the increase in intestinal tumors in obese individuals.

Tight junctions are structures in-between IECs and a key element of a tight leak-proof barrier $(36,37)$. The expression of junctional proteins in the intestine is tightly regulated, and the complex pattern is associated with the specific functions of a particular intestinal region and localization (38). The Claudin family of proteins is more complex than other tight junction proteins, and a total of 24 distinct Claudin family gene members have been identified in humans to date (39). Claudins exhibit distinct tissue-, cell- and developmental stage-specific expression patterns $(40,41)$. Claudin- 2 is restricted to undifferentiated crypt cells and is undetectable in the normal colon, but is upregulated along an inflamed crypt epithelium $(42,43)$. This may explain the increase in Claudin-2 expression that was observed in mice fed an HFD in the present study, as compared with the control mice.

In conclusion, the data of the present study suggested that an HFD results in changes to the regulation of the stemness of ISCs and to the epithelial barrier function of 
the colon. Thus, dietary intervention may be an effective strategy for reducing the risk of colon cancer and other systemic diseases, such as cardiovascular diseases and metabolic syndrome. Further research should focus on understanding the mechanisms through which nutrients impact other tissues via the intestine.

\section{Acknowledgements}

Not applicable.

\section{Funding}

The present study was supported by grants from the National Natural Science Foundation of China (grant. no. 91649122) and the National Natural Science Youth Foundation of China (grant. no. 81600688).

\section{Availability of data and materials}

The datasets used and/or analyzed during the present study are available from the corresponding author on reasonable request.

\section{Authors' contributions}

GD and JY conceived and designed the study. FD, YX, WD and YL performed the experiments. FX and YS analyzed the data. JY wrote the manuscript.

\section{Ethics approval and consent to participate}

The experimental protocols of the present study were approved by the Animal Care and Use Committee of Nanjing Medical University (Nanjing, China), and conducted in accordance with the guidelines of this committee.

\section{Patient consent for publication}

Not applicable.

\section{Competing of interests}

The authors declare that they have no competing interests.

\section{References}

1. Nagao M, Asai A, Sugihara H and Oikawa S: Fat intake and the development of type 2 diabetes. Endocr J 62: 561-572, 2015.

2. Schulz MD, Atay C, Heringer J, Romrig FK, Schwitalla S, Aydin B, Ziegler PK, Varga J, Reindl W, Pommerenke C, et al: High-fat-diet-mediated dysbiosis promotes intestinal carcinogenesis independently of obesity. Nature 514: 508-512, 2014.

3. Bleau C, Karelis AD, St-Pierre DH and Lamontagne L: Crosstalk between intestinal microbiota, adipose tissue and skeletal muscle as an early event in systemic low-grade inflammation and the development of obesity and diabetes. Diabetes Metab Res Rev 31: 545-561, 2015.

4. David LA, Maurice CF, Carmody RN, Gootenberg DB, Button JE, Wolfe BE, Ling AV, Devlin AS, Varma Y, Fischbach MA, et al: Diet rapidly and reproducibly alters the human gut microbiome. Nature 505: 559-563, 2014

5. Wu GD, Chen J, Hoffmann C, BittingerK, Chen YY,Keilbaugh SA, Bewtra M, Knights D, Walters WA, Knight R, et al: Linking long-term dietary patterns with gut microbial enterotypes. Science 334: 105-108, 2011.
6. Backhed F, Ley RE, Sonnenburg JL, Peterson DA and Gordon JI: Host-bacterial mutualism in the human intestine. Science 307: 1915-1920, 2005

7. Qin N, Yang F, Li A, Prifti E, Chen Y, Shao L, Guo J, Le Chatelier E, Yao J, Wu L, et al: Alterations of the human gut microbiome in liver cirrhosis. Nature 513: 59-64, 2014.

8. Carmody RN, Gerber GK, Luevano JM Jr, Gatti DM, Somes L, Svenson KL and Turnbaugh PJ: Diet dominates host genotype in shaping the murine gut microbiota. Cell Host Microbe 17: 72-84, 2015.

9. Kurashima Y, Goto Y and Kiyono H: Mucosal innate immune cells regulate both gut homeostasis and intestinal inflammation. Eur J Immunol 43: 3108-3115, 2013.

10. Bjerregaard LG, Jensen BW, Angquist L, Osler M, Sorensen TIA and Baker JL: Change in overweight from childhood to early adulthood and risk of type 2 diabetes. N Engl J Med 378: 1302-1312, 2018.

11. Feldman AT and Wolfe D: Tissue processing and hematoxylin and eosin staining. Methods Mol Biol 1180: 31-43, 2014.

12. Dame MK and Varani J: Human colon tissue in organ culture. In: Replacing animal models. Davies J (ed). John Wiley \& Sons, Inc., Hoboken, NJ, pp69-80, 2012.

13. Sato T and Clevers H: Primary mouse small intestinal epithelial cell cultures. Methods Mol Biol 945: 319-328, 2013

14. Sato T, Vries RG, Snippert HJ, van de Wetering M, Barker N, Stange DE, van Es JH, Abo A, Kujala P, Peters PJ and Clevers H: Single Lgr5 stem cells build crypt-villus structures in vitro without a mesenchymal niche. Nature 459: 262-265, 2009.

15. Date S and Sato T: Mini-gut organoids: Reconstitution of the stem cell niche. Annu Rev Cell Dev Biol 31: 269-289, 2015.

16. Koo BK, Sasselli V and Clevers H: Retroviral gene expression control in primary organoid cultures. Curr Protoc Stem Cell Biol 27: Unit 5A.6, 2013.

17. Sato T, van Es JH, Snippert HJ, Stange DE, Vries RG, van den Born M, Barker N, Shroyer NF, van de Wetering M and Clevers H: Paneth cells constitute the niche for Lgr5 stem cells in intestinal crypts. Nature 469: 415-418, 2011.

18. Beyaz S, Mana MD, Roper J, Kedrin D, Saadatpour A, Hong SJ, Bauer-Rowe KE, Xifaras ME, Akkad A, Arias E, et al: High-fat diet enhances stemness and tumorigenicity of intestinal progenitors. Nature 531: 53-58, 2016.

19. Livak KJ and Schmittgen TD: Analysis of relative gene expression data using real-time quantitative PCR and the 2(-Delta Delta C(T)) method. Methods 25: 402-408, 2001.

20. Merker SR, Weitz J and Stange DE: Gastrointestinal organoids: How they gut it out. Dev Biol 420: 239-250, 2016.

21. Peterson LW and Artis D: Intestinal epithelial cells: Regulators of barrier function and immune homeostasis. Nat Rev Immunol 14: 141-153, 2014.

22. Johansson ME, Phillipson M, Petersson J, Velcich A, Holm L and Hansson GC: The inner of the two Muc2 mucin-dependent mucus layers in colon is devoid of bacteria. Proc Natl Acad Sci USA 105: 15064-15069, 2008.

23. Vancamelbeke $M$ and Vermeire S: The intestinal barrier: A fundamental role in health and disease. Expert Rev Gastroenterol Hepatol 11: 821-834, 2017.

24. Ahmad R, Sorrell MF, Batra SK, Dhawan P and Singh AB: Gut permeability and mucosal inflammation: Bad, good or context dependent. Mucosal Immunol 10: 307-317, 2017.

25. Assimakopoulos SF, Papageorgiou I and Charonis A: Enterocytes' tight junctions: From molecules to diseases. World J Gastrointest Pathophysiol 2: 123-137, 2011.

26. Matheson PJ, Wilson MA and Garrison RN: Regulation of intestinal blood flow. J Surg Res 93: 182-196, 2000.

27. Mihaylova MM, Sabatini DM and Yilmaz OH: Dietary and metabolic control of stem cell function in physiology and cancer. Cell Stem Cell 14: 292-305, 2014.

28. Dunel-Erb S, Chevalier C, Laurent P, Bach A, Decrock F and Le Maho Y: Restoration of the jejunal mucosa in rats refed after prolonged fasting. Comp Biochem Physiol A Mol Integr Physiol 129: 933-947, 2001.

29. Mao J, Hu X, Xiao Y, Yang C, Ding Y, Hou N, Wang J, Cheng H and Zhang X: Overnutrition stimulates intestinal epithelium proliferation through $\beta$-catenin signaling in obese mice. Diabetes 62: 3736-3746, 2013.

30. Baldassano S, Amato A, Cappello F, Rappa F and Mule F: Glucagon-like peptide-2 and mouse intestinal adaptation to a high-fat diet. J Endocrinol 217: 11-20, 2013.

31. Basen-Engquist $\mathrm{K}$ and Chang M: Obesity and cancer risk: Recent review and evidence. Curr Oncol Rep 13: 71-76, 2011. 
32. Calle EE and Kaaks R: Overweight, obesity and cancer: Epidemiological evidence and proposed mechanisms. Nat Rev Cancer 4: 579-591, 2004.

33. Berger NA: Obesity and cancer pathogenesis. Ann N Y Acad Sci 1311: 57-76, 2014

34. Yilmaz OH, Katajisto P, Lamming DW, Gültekin Y, Bauer-Rowe KE, Sengupta S, Birsoy K, Dursun A, Yilmaz VO, Selig M, et al: $\mathrm{mTORC1}$ in the Paneth cell niche couples intestinal stem-cell function to calorie intake. Nature 486: 490-495, 2012.

35. Zhou W, Davis EA, Li K, Nowak RA and Dailey MJ: Sex differences influence intestinal epithelial stem cell proliferation independent of obesity. Physiol Rep 6: e13746, 2018

36. Suzuki T: Regulation of intestinal epithelial permeability by tight junctions. Cell Mol Life Sci 70: 631-659, 2013.

37. Menard S, Cerf-Bensussan N and Heyman M: Multiple facets of intestinal permeability and epithelial handling of dietary antigens. Mucosal Immunol 3: 247-259, 2010.

38. Laukoetter MG, Bruewer M and Nusrat A: Regulation of the intestinal epithelial barrier by the apical junctional complex. Curr Opin Gastroenterol 22: 85-89, 2006.
39. Tsukita S, Furuse $\mathrm{M}$ and Itoh M: Multifunctional strands in tight junctions. Nat Rev Mol Cell Biol 2: 285-293, 2001.

40. Ebnet K, Suzuki A, Ohno S and Vestweber D: Junctional adhesion molecules (JAMs): More molecules with dual functions? J Cell Sci 117: 19-29, 2004.

41. Bazzoni G: The JAM family of junctional adhesion molecules. Curr Opin Cell Biol 15: 525-530, 2003.

42. Heller F, Florian P, Bojarski C, Richter J, Christ M, Hillenbrand B, Mankertz J, Gitter AH, Bürgel N, Fromm M, et al: Interleukin-13 is the key effector Th2 cytokine in ulcerative colitis that affects epithelial tight junctions, apoptosis, and cell restitution. Gastroenterology 129: 550-564, 2005.

43. Lu Z, Ding L, Lu Q and Chen YH: Claudins in intestines: Distribution and functional significance in health and diseases. Tissue Barriers 1: e24978, 2013.

This work is licensed under a Creative Commons Attribution-NonCommercial-NoDerivatives 4.0 International (CC BY-NC-ND 4.0) License. 